\title{
PREDICTABILITY OF HAND SKILL AND COGNITIVE ABILITIES FROM CRANIOFACIAL WIDTH IN RIGHT- AND LEFT-HANDED MEN AND WOMEN: RELATION OF SKELETAL STRUCTURE TO CEREBRAL FUNCTION
}

ERTUNC DAYI

Ataturk University

School of Dentistry

Erzurum, Turkey

\author{
MUKADDER OKUYAN \\ UNER TAN \\ BlackSea Technical University \\ School of Medicine \\ Trabzon, Turkey
}

\begin{abstract}
Recently, a family of homeobox genes involved in brain and craniofacial development was identified. In light of this genetic background, we hypothesized that some functional characteristics of human brain (hand skill, cognition) may be linked to some structural characteristics of human skull (e.g., craniofacial width) in humans. Hand preference was assessed by Oldfield's Handedness Questionnaire. Hand skill was measured by Peg Moving Task. Face width was measured from the anteroposterior cephalograms ( $x$-ray) using right $(R)$ and left $(L)$ zygomatic points. Intelligence " $g$ " was assessed by Cattell's Culture Fair Intelligence Test; the perceptual-verbal ability was assessed by "Finding A's Test"; the spatial ability was assessed by the mental rotation task, in right- and left-handed men and women. The percentages of right-,
\end{abstract}

Received 17 October 2001.

Address correspondence to Prof. Dr. Uner Tan, BlackSea Technical University (KTU), School of Medicine, Department of Physiology, Trabzon, Turkey. E-mail: unertan@meds.ktu.edu.tr or unertan100@netscape.net. 
left-, and mixed-faced subjects were close to those found for paw preference in cats. Women tended to be more right-faced $(R-L>0)$ and less left-faced $(R-L<0)$ than men, who tended to be more left-faced and less right-faced than women. $R-L$ face width inversely correlated with $L-R$ PMT (peg moving time) in left-handers; there was a direct relation between these variables in right-handers. Cattell IQ linearly increased with $R-L$ face width in left-handers, negatively correlated in right-handed men and women. Verbal ability inversely related to $R-L$ face width in right- and left-handed men, but directly correlated in right-handed women. The number of correct response on mental-rotation task positively and linearly correlated with $R-L$ face width in lefthanders and right-handed women. It was concluded that the structuralfunctional coupling revealed in the present work may have its origins in parallel development of the craniofacial skeleton and brain under the influence of homeobox genes.

Keywords brain, cognition, craniofacial region, genetics, hand skill, sex difference

We have hypothesized that some functional characteristics of the human brain, such as hand skill and cognition, may be linked to some structural characteristics of the human face (craniofacial skeleton). This hypothesis was tested in the present work.

Concerning the coupling between structure and function, it was frequently reported that brain size would be a good predictor for dental development (Godfrey, Samonds, Jungers, \& Sutherland, 2001): dental development may be prolonged as an incidental effect of prolonged brain growth, suggesting a link between the developments of the craniofacial region (structure) and the brain (motor and cognitive functions). In this context, Down syndrome may be considered a prototype for the coupling between structure and function. Down syndrome is a congenital disorder due to trisomy of chromosome 21 , which results in an immaturity of the nervous system and the craniofacial region, especially the maxilla (Handoll, 1998). The abnormalities in the craniofacial morphology were frequently reported in the face of Down syndrome patients (e.g., Cohen et al., 1995; Farkas, Munro, \& Kolar, 1985; Farkas, Katic, Forrest, \& Litsas, 2001).

The coupling between the craniofacial morphometry and brain may have genetic origins. Accordingly, there are genes exhibiting multiple functions at different stages of development or in different tissues and cell types. Blaschke et al. (1998) have identified a 
human paired-related homeobox gene, SHOT, which is implicated in craniofacial, brain, heart, and limb development. Merlo et al. (2000) have reported that DIx genes, comprising a highly conserved family of homeobox genes, are expressed in spatially and temporally restricted patterns in craniofacial primordia, basala telencephalon, and diencephalon, and in distal regions of extending appendages, including the limb and the genital bud; these genes seem to have multiple functions at different stages of development or in different tissues and cell types. Dirksen, Mathers, and Jamrich (1993) have reported that expression of a Xenopus distal-less homeobox gene is involved in forebrain and craniofacial development. In light of this genetic background, it is justified to propose that craniofacial morphology may be related to cerebral functioning (e.g., hand skill and cognition). To test this working hypothesis (also see above), the relation of the craniofacial width to hand skill (peg moving task) and cognitive abilities (Cattell's Culture Fair Intelligence Test, perceptual-verbal ability, and mental rotation ability) were analyzed in right- and left-handed male and female subjects. The present work is the first study considering the relations of cerebral functions, such as motor skill and cognitive abilities, to craniofacial morphology (right and left facial widths). In this context, there are studies indicating an average correlation $(r=.44)$ between IQ and the skull size (for review, see Rushton \& Ankney, 1996). Tan et al. (1999) have reported for the first time that IQ-brain size relation needs qualification. These authors have also found a correlation coefficient of .40 between IQ (Cattell) and magnetic resonance imaging (MRI)measured total midsagittal cerebral area, which showed variations if the results were reanalyzed, taking into consideration the sex and handedness of the subjects: There was no significant correlation between the cranial capacity and IQ (Cattell) in right-handed men; men's IQ significantly correlated only with the anterior cerebral areas, whereas women's IQ correlated especially with the posterior cerebral areas.

\section{METHODS AND RESULTS}

The participants were male and female students from the School of Dentistry of Ataturk University, Erzurum, Turkey. The age of the 
subjects ranged from 19 to 22 years. The subjects were seated in a chair and the head oriented in the Frankfort plane; posteroanterior radiographic cephalograms with teeth in centric occlusion were taken using a standardized cephalometric technique. The central ray of $\mathrm{x}$-rays passed through the center of the midsagittal plane so that the magnification of the right and left sides of the face was the same. The right and left zygomatic points were marked on the cephalograms and joined by a horizontal line. The vertical midline of the face was determined by taking the anatomical axis of the head. The right and left face widths were measured to the nearest $0.5 \mathrm{~mm}$. The SPSS statistical package was used to analyze the data statistically. In addition to the mean and standard deviation, the effect size $(e)$ was also evaluated.

Table 1 presents the mean and standard deviation for the right and left face widths, and the right minus left $(\mathrm{R}-\mathrm{L})$ face widths in the right- and left-handed male and female subjects. To assess hand preference, all subjects received the Turkish version of Oldfield's Handedness Questionnaire (Tan, 1988). The right-handed subjects had Geschwind Scores (Tan, 1988) of +100 (consistent right-handers), and the left-handed subjects had Geschwind Scores of -100 (consistent left-handers). The women were right-handed $(N=25)$; there were 10 left-handed men and 17 right-handed men.

The multivariate analysis indicated that sex and handedness were significant factors influencing the right, left, and $\mathrm{R}-\mathrm{L}$ face widths, but Sex $\times$ Handedness interaction was nonsignificant (sex: $F=5.7$,

TABLE 1. Mean and standard deviation for the right, left, and $\mathrm{R}-\mathrm{L}$ face widths $(\mathrm{mm})$ of right- and left-handed men and women

\begin{tabular}{|c|c|c|c|c|c|c|c|}
\hline \multirow[b]{2}{*}{ Subjects } & \multirow[b]{2}{*}{$N$} & \multicolumn{2}{|c|}{ Right } & \multicolumn{2}{|c|}{ Left } & \multicolumn{2}{|c|}{$R-L$} \\
\hline & & Mean & $S D$ & Mean & $S D$ & Mean & $S D$ \\
\hline Men & 24 & 72.6 & 8.2 & 71.8 & 8.8 & 0.81 & 4.9 \\
\hline RHs & 14 & 72.7 & 9.1 & 72.8 & 6.9 & 0.1 & 4.3 \\
\hline LHs & 10 & 72.1 & 4.4 & 68.5 & 10.3 & 3.6 & 4.8 \\
\hline Women & 29 & 69.9 & 4.7 & 69.6 & 6.7 & 0.36 & 2.9 \\
\hline RHs & 25 & 70.1 & 4.9 & 70.1 & 7.1 & 0.04 & 4.7 \\
\hline LHs & 4 & 68.0 & 2.2 & 64.0 & 2.3 & 4.00 & 4.6 \\
\hline
\end{tabular}

RHs: right-handers; LHs: left-handers; Right: right face width; Left: left face width; R - L: right minus left face width. 
$p=.005, e=.12$; handedness: $F=9.0, p<.001, e=.17$; Sex $\times$ Handedness: $F=0.31, p>.50)$. Tests of between-subject effects showed that the mean right and left face widths were significantly larger in men than women $(F=8.8$ and $8.5, p<.005$ for the right and left face widths), but the $\mathrm{R}-\mathrm{L}$ face width did not exhibit any significant sex difference $(F=0.04, p>.80)$. For handedness, there was no significant difference between the right face widths of the right- and left-handers $(F=1.4, p>.20)$, but the left face width was significantly larger in the right- than the left-handed subjects $(F=$ $17.2, p<.001, e=.16)$; the $\mathrm{R}-\mathrm{L}$ face width was significantly greater in the left- than the right-handers $(F=10.1, p<.005, e=$ .10). Sex was found to be a significant factor for the heights of the subjects $(F=81.1, p<.001, e=.53)$ : Men were significantly taller than women. The significant sex difference disappeared if the face widths were evaluated at the covariance of height $(F=$ $.13, p>.80)$; only handedness remained a significant factor influencing the face width measurements $(F=9.8, p<.001, e=.19)$ : There was no significant difference between the mean right face widths of the right- and left-handers $(F=1.4, p>.20)$, whereas the left face width was significantly greater in right-handers than left-handers $(F=19.2, p<.001, e=.18)$. Sex $\times$ hand interaction was found to be statistically significant $(F=10.0, p<.005, e=$ $.10)$.

The subjects with the $\mathrm{R}-\mathrm{L}$ face widths $>0$ were considered right-faced subjects, and those with the $\mathrm{R}-\mathrm{L}$ face widths were considered left-faced subjects. In doing so, it was found in women $(N=27)$ that $57.7 \%$ were right-faced, $38.5 \%$ left-faced, and $3.8 \%$ symmetric-faced $(\mathrm{R}-\mathrm{L}=0)$; in men $(N=17)$, $43.5 \%$ were rightfaced, $52.2 \%$ left-faced, and $4.3 \%$ symmetric-faced. Although women seemed to exceed men in right-facedness and men exceed women in left-facedness, the difference between the numbers of the right-, left-, and symmetric male and female subjects was statistically nonsignificant $\left(\chi^{2}=2.6, p>.05\right)$. There were two extreme values in the men and women data. After excluding these data, the $\mathrm{R}-\mathrm{L}$ face widths were found to be $0.74 \pm 2.46$ and $-0.23 \pm 4.4 \mathrm{~mm}$ for women and men, respectively. These results indicated that women tended to be more right-faced than men and men were more left-faced than women $(t=1.8, p<.10)$. 


\section{Dependence of $\mathbf{R}$ - $\mathbf{L}$ Face Width on the Right and Left Face Widths}

\section{Left-Handed Men}

Because of the very small sample size $(N=3)$, the female lefthanders were not subjected to a statistical analysis. Only the lefthanded male subjects were considered in the present work. The upper scattergram in Figure 1 illustrates the relation of the $\mathrm{R}-\mathrm{L}$ face width (ordinate) to the right (abscissa, closed circles) and left face width (abscissa, open circles, thick straight line) in the lefthanded men. The $\mathrm{R}-\mathrm{L}$ face width did not significantly depend on the right face width $(r=.07, p>.05)$. The left-face width correlated negatively and linearly with the $\mathrm{R}-\mathrm{L}$ face width $(r=.84, t=-4.4$, $p<.005)$ : The $\mathrm{R}-\mathrm{L}$ face width increased in favor of right-facedness as the left face width decreased, and the $\mathrm{R}-\mathrm{L}$ face width decreased in favor of left-facedness as the left face width increased.

\section{Right-Handed Women}

The middle diagram in Figure 1 illustrates the relation of the $\mathrm{R}-\mathrm{L}$ face width (ordinate) to the right face width (abscissa, closed circles, straight line) and the left face width (abscissa, open circles, dashed line) in right-handed female subjects. The $\mathrm{R}-\mathrm{L}$ face width significantly related only to the left face width (negative, linear correlation: $r=.69, t=-4.8, p<.001)$ : The facial width asymmetry decreased in favor of left-facedness as the left face width increased; the facial width asymmetry increased in favor of right-facedness as the left face width decreased. There was no significant correlation between the $\mathrm{R}-\mathrm{L}$ face width and the right face width in righthanded women $(r=.13, t=0.64, p>.50)$.

\section{Right-Handed Men}

The lower diagram in Figure 1 illustrates the relations of the $\mathrm{R}-\mathrm{L}$ face width (ordinate) to the right face width (abscissa, closed circles, straight line) and the left face width (abscissa, open circles, dashed line). There was a positive linear correlation between the $\mathrm{R}-\mathrm{L}$ face width and right face width $(r=.88, t=7.1, p<.001)$ : The facial 

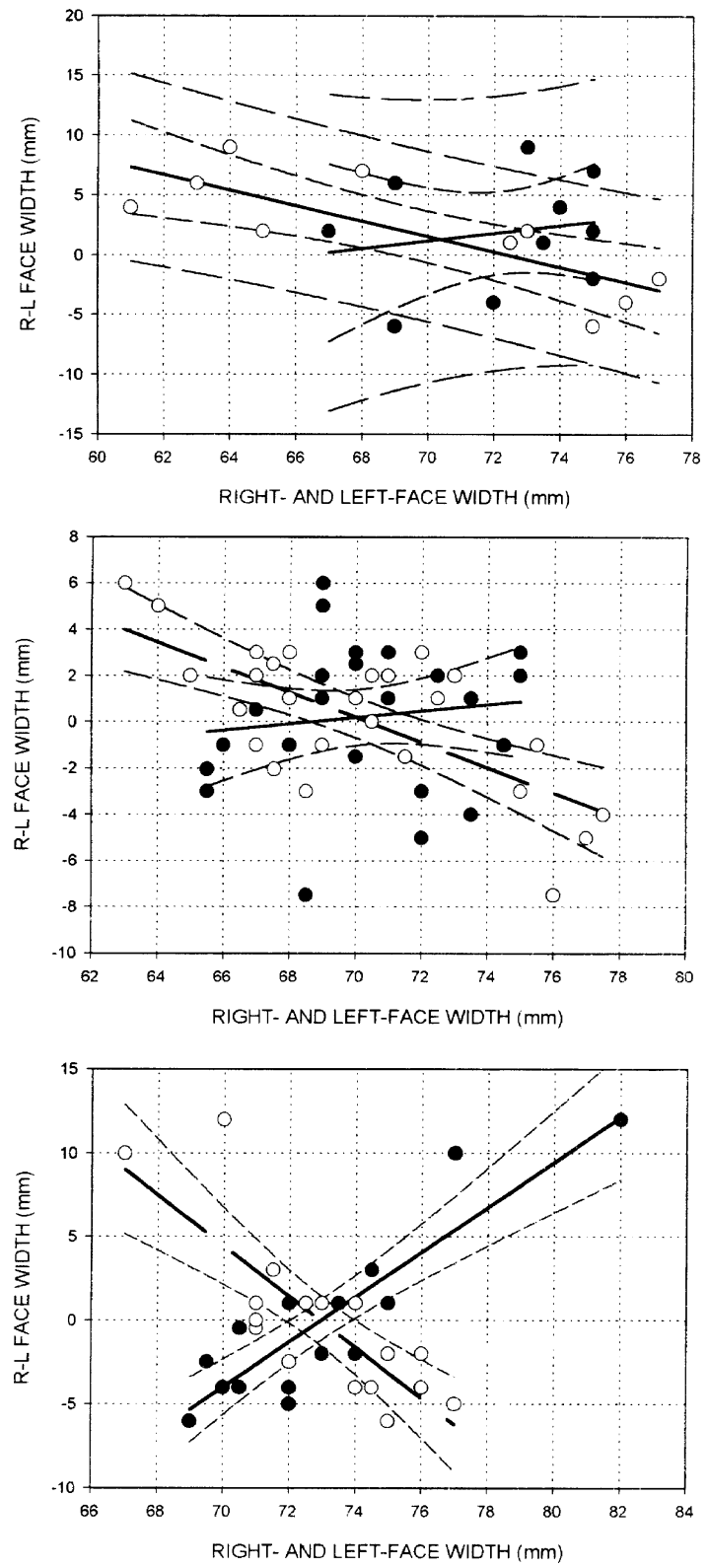

FIGURE 1. Relations of $\mathrm{R}-\mathrm{L}$ face width (ordinate) to right and left face widths (abscissa) in the left-handed men (upper), right-handed women (middle), and righthanded men (lower). 
width asymmetry increased in favor of left-facedness as the right face width decreased; the facial asymmetry increased in favor of right-facedness as the right face width increased. There was a negative linear correlation between the $\mathrm{R}-\mathrm{L}$ face width and the left face width $(r=.81, t=-5.3, p<.001)$ : The right-facedness increased as the left face with decreased; the right-facedness decreased in favor of left-facedness as the left face width increased.

\section{Dependence of Left Minus Right $(\mathrm{L}-\mathrm{R})$ Peg Moving Time (PMT) to R - L Face Width}

The hand skill (visuomotor skill and coordination) was evaluated by the peg moving task (Tan, 1989b). To assess hand skill, a peg board was used, consisting of two parallel rows of 25 holes and 25 loosefitting dwelling pegs in one row on the right side. The subjects were required to shift these pegs to the corresponding opposite holes on the left side using the right hand as fast as possible. They then moved the pegs from the left side to the right side using the left hand as fast as possible. This was the first trial. Ten trials were performed by each hand and the mean PMTs were calculated for the right and left hands. The L - R PMTs were calculated by subtracting the mean PMT for the left hand from the mean PMT for the right hand. The mean $\mathrm{L}-\mathrm{R}$ PMT was greater than zero in righthanders, and smaller than zero in left-handers.

Figure 2 illustrates the relation between the L $-\mathrm{R}$ PMT (ordinate) and the $\mathrm{R}-\mathrm{L}$ face width (abscissa) in left-handed male subjects (top) and in right-handed subjects (bottom). In left-handed men, there was a negative linear correlation between the L - R PMT and the $\mathrm{R}-\mathrm{L}$ face width $(r=.82, t=-4.1, p<.005)$ : The left-hand skill progressively increased as the left-facedness decreased and the rightfacedness increased; the left-hand skill progressively decreased as the right-facedness decreased and the left-facedness increased.

In the right-handed subjects $(N=42)$, the $\mathrm{L}-\mathrm{R}$ PMT positively and linearly correlated with the $\mathrm{R}-\mathrm{L}$ face width $(r=.54, t=3.9$, $p<.001)$. The male and female right-handers were presented together, because the relations exhibited similar patterns: For the right-handed men, $r=.52, t=2.2, p<.05$; for the right-handed women, $\mathrm{N}=17, r=.60, t=3.3, p<.005$. The relation between the 

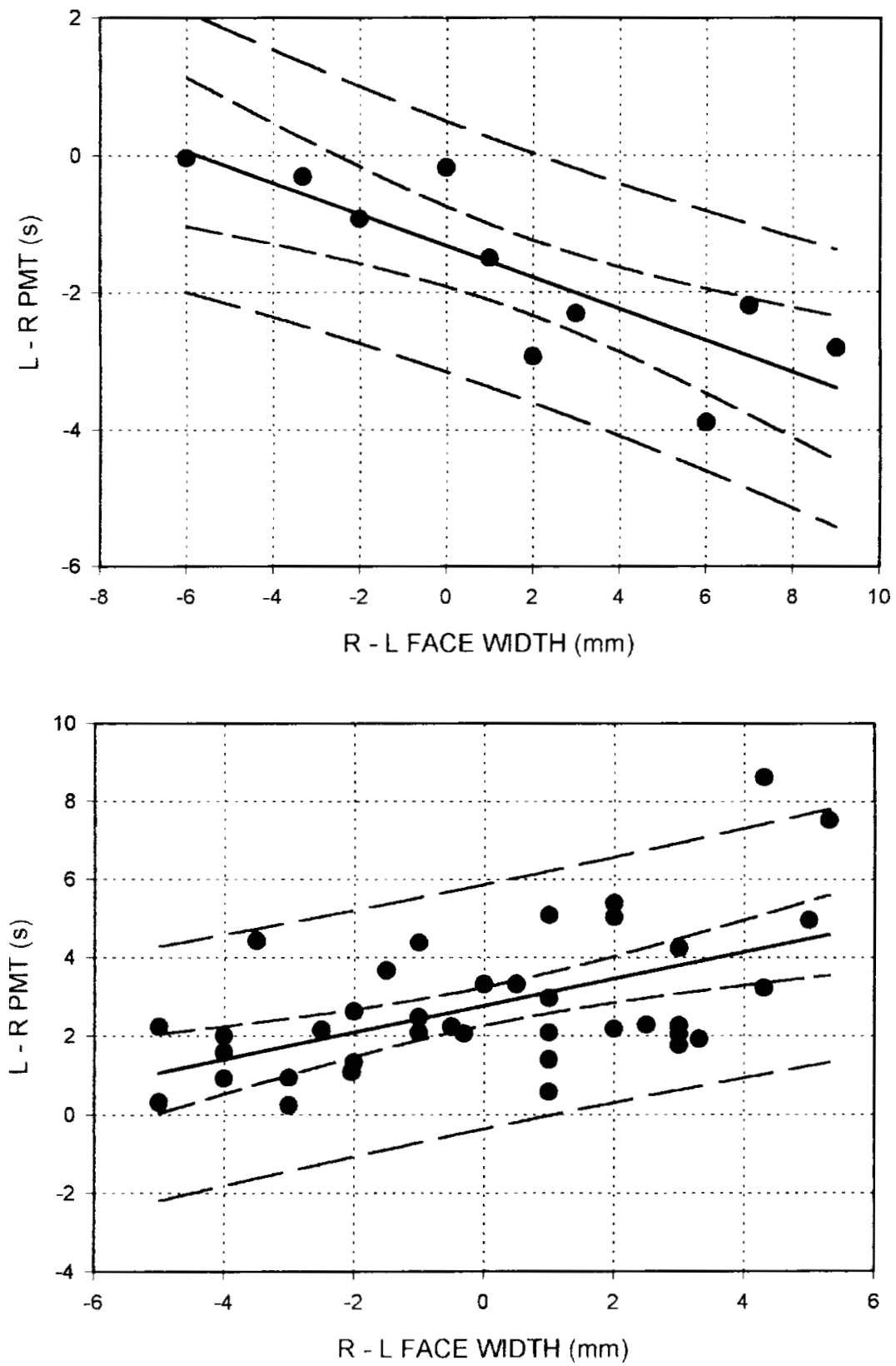

FIGURE 2. Relations of the $\mathrm{L}-\mathrm{R}$ PMT (ordinate) to $\mathrm{R}-\mathrm{L}$ face width (abscissa) for left-handed men (top), and right-handed subjects (bottom). 
L - R PMT and the R - L face width was opposite to that for the left-handers, namely, the right-hand skill increased as the left-facedness decreased and the right-facedness increased; the right-hand skill decreased as the right-facedness decreased and the left-facedness increased.

\section{Cattell's Culture Fair Intelligence Test and Right Minus Left Face Width}

The cognitive abilities were assessed by using three well-known tests: Cattell's Culture Fair Intelligence Test, Finding A's Test, and the mental rotation test. The first one was designed to be a general measure of inborn intelligence without utilizing the verbal material (Cattell, 1987). This test primarily measures fluid intelligence, partwhole relations, similarities, causal relations spatial relations, inductive reasoning, and inferential relations, and includes series, classification, matrices, and topology. We used the IPAT Culture Fair Intelligence Test, Scale 3A. There are no significant sex differences in this test (see also Halpern \& Tan, 2001; Tan \& Tan, 1998) and spatial ability seems to be the most important factor with some loading on verbal and numerical abilities (Cattell, 1987). This test was administered to all 2nd year dental students who attended the practical sessions. The females were in the midluteal phase of the menstrual cycle during the application of this test. This was important because the Cattell IQ was found to show fluctuations during the menstrual cycle (Halpern \& Tan, 2001).

\section{Left-Handed Men ( $=10)$}

The upper diagram in Figure 3 illustrates the relations between IQ (ordinate) and the face widths (abscissa) in left-handed male subjects. IQ directly but nonsignificantly correlated with the right face width $(r=.25, t=0.75, p>.40)$. There was a significant quadratic relation (inverse $\mathrm{U}$ ) between IQ and the left face width (middle diagram; $\left.r=.88, F_{3,7}=7.0, p<.05\right)$. There was an optimum face width with highest "g." IQ positively linearly correlated with the $\mathrm{R}-\mathrm{L}$ face width (bottom diagram; $r=.82, t=4.1, p<.005$ ). That is, fluid intelligence increased as the left-facedness decreased and the right-facedness increased (see also the upper diagram). 



FIGURE 3. Relation of Cattell IQ (ordinate) to the right face width (upper), left face width (middle), and the $\mathrm{R}-\mathrm{L}$ face width (lower) in left-handed male subjects. 


\section{Right-Handed Men and Women}

In the female subjects, the Cattell IQ showed a negative linear correlation with the $\mathrm{R}-\mathrm{L}$ face width $(r=.57, t=-3.0, p<.01)$; IQ increased as the right-facedness decreased and the left-facedness increased; IQ decreased as the right-facedness increased and the left-facedness decreased. In the male subjects, the $\mathrm{R}-\mathrm{L}$ face width directly correlated with IQ as in the female subjects $(r=.70, t=3.5, p<.005)$ : IQ linearly increased as the left-facedness decreased and the rightfacedness increased; IQ decreased as the right-facedness decreased and the left-facedness increased.

Figure 4 illustrates the correlations between IQ (ordinate) and the right face width (closed circles, straight line) and the left face width (open circles, dashed lines) in women (top diagram) and men (bottom diagram). In women, IQ directly correlated with the right face width $(r=.88, t=7.5, p<.001)$, but there was no significant correlation between IQ and the left face width $(r=.13, t=0.6, p>$ $.50)$. IQ positively linearly increased as the right face width increased; IQ significantly related only to the right face width in the right-handed female subjects. In men, IQ directly correlated with the right face width $(r=.62, t=3.1, p<.001)$, and inversely correlated with the left face width $(r=.56, t=-2.5, p<.05)$. IQ directly increased as the right face width increased; IQ linearly decreased as the left face width increased.

\section{Dependence of Perceptual-Verbal Ability on R - L Face Width}

Perceptual-verbal ability was assessed by the Finding A's Test (Turkish Language Version; see also Halpern \& Tan, 2001). Females are better than males in this test (Kimura \& Hampson, 1994), which includes words extending across several pages. The participants' task is to read the words as fast as possible, crossing out the letter "a" whenever it appears in the list of words. In doing this, the reading speed and knowledge of spelling is tested because in the current study it is a timed test, which is usually described as a test of perceptual speed. The participants were 2nd year dental students. The women scored significantly higher than the males, as found with the English version. This test was applied to the female 

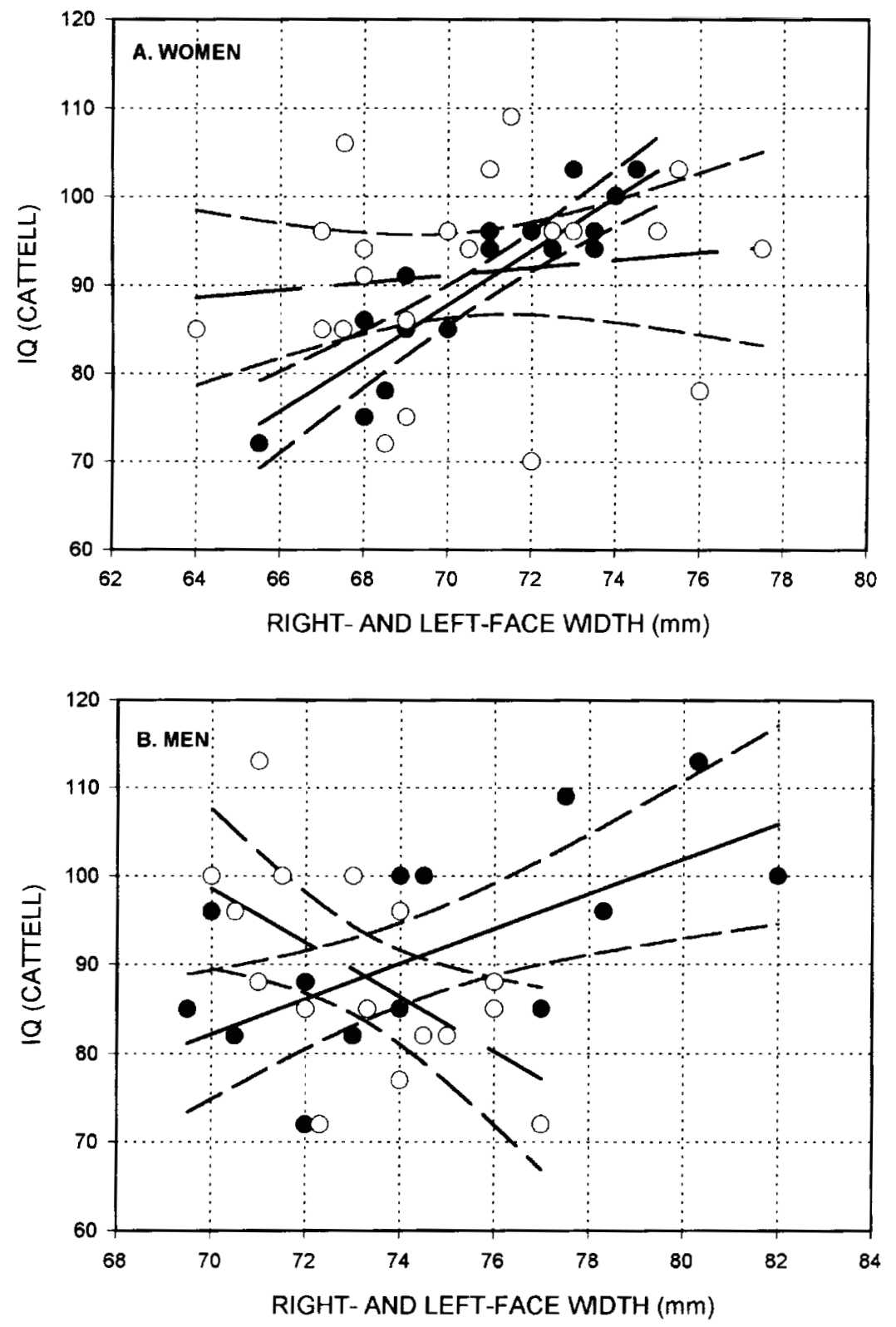

FIGURE 4. Relations of Cattell IQ (ordinate) to right and left face widths (abscissa) in right-handed female (A) and male (B) subjects. Closed circles, straight line: right face width; open circles, dashed line: left face width. 
subjects during the midluteal phase of the menstrual cycle, because the test results depend upon the cycle day in women (Halpern \& Tan, 2001).

\section{Left-Handed Men}

Figure 5 illustrates the relation of the perceptual-verbal ability to the $\mathrm{R}-\mathrm{L}$ face width (top), the right face width (bottom, closed circles, straight line), and the left face width (bottom, open circles, dashed line) in left-handed men. As seen in the upper diagram, the number correct on As decreased as the $\mathrm{R}-\mathrm{L}$ face width increased toward the right-facedness, and increased as the $\mathrm{R}-\mathrm{L}$ face width increased toward the left-facedness. That is, there was a negative, linear correlation between the number correct on As and the $\mathrm{R}-\mathrm{L}$ face width $(r=.61, t=-2.8, p<.05)$. As seen in the bottom diagram, the number correct on As positively and linearly increased as the right face width increased. That is, there was a positive, linear correlation between the number of As correct and the right face width $(r=.61, t=2.6, p<.05)$. The relation between the As correct and the left face width was found to be statistically nonsignificant $(r=.07, t=0.24, p>.80)$.

\section{Perceptual-Verbal Ability (A's Test) in Right-Handed Men}

Figure 6A illustrates the relation of the number correct on As (ordinate) with the $\mathrm{R}-\mathrm{L}$ face width (abscissa). There was a negative, linear correlation between these two variables $(r=.67, t=-3.1, p=$ $.01)$ : The number correct on As decreased as the right-facedness increased; the number correct on As increased as the left-facedness increased in right-handed men. Figure $6 \mathbf{B}$ illustrates the relation between the number correct on As and the right face width (closed circles, straight line), and left face width (open circles, dashed line). The number correct on As linearly increased as the right face width increased $(r=.61, t=2.6, p<.05)$; there was no significant relation between the number correct on As and the left face width $(r=.08$, $t=-0.2, p>.80)$. 

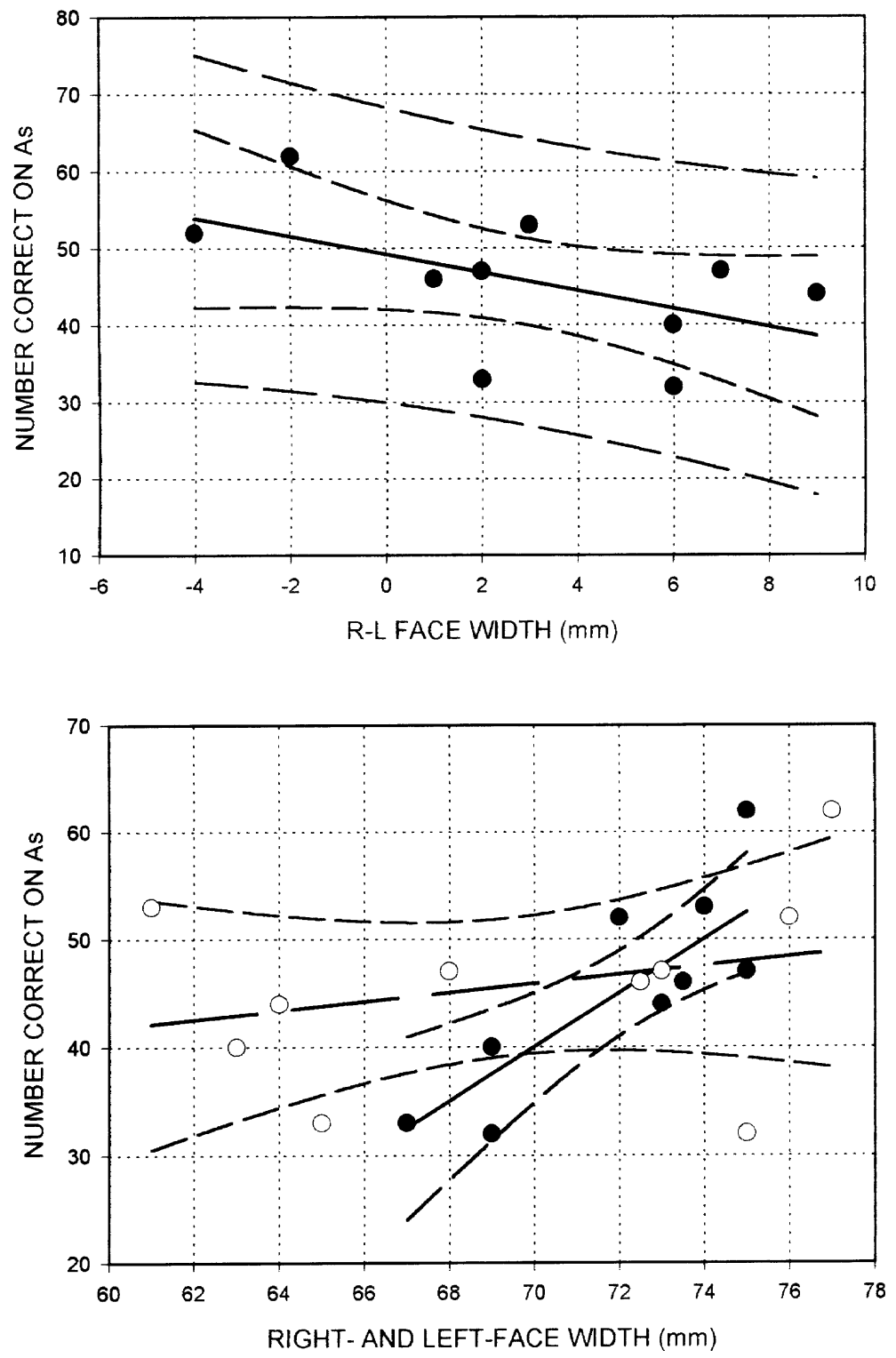

FIGURE 5. Relation of number correct on As (Finding A's test) to $\mathrm{R}-\mathrm{L}$ face width (top), and right and left face widths (bottom) in left-handed subjects. Ordinate: number correct on As; abscissa: $\mathrm{R}$ - L face width (top), and the right (closed circles, straight line) and left face (open circles, dashed line) widths (bottom). 



FIGURE 6. Relations of the number correct on As (perceptual-verbal test) to the R $\mathrm{L}$ face widths (A: right-handed men; C: right-handed women), right face width (B: right-handed men, closed circles, straight line; D: right-handed women, closed circles, straight line), and left face width (B and D: open circles, dashed line).

\section{Perceptual-Verbal Ability (A's Test) in Right-Handed Women}

Figure $6 \mathbf{C}$ illustrates the relation of the number correct on As with the $\mathrm{R}-\mathrm{L}$ face width in right-handed women. This relation was a direct one, that is, the number correct on As increased as the rightfacedness increased and decreased as the left-facedness increased $(r=.51, t=2.7, p<.05)$. Figure $6 \mathbf{D}$ illustrates the relation of the number correct on As (ordinate) to the right (closed circles, straight line) and left face width (open circles, dashed line). The right face width directly correlated with the number correct on As $(r=.60, t=$ $3.3, p<.005)$, but the relation of the number correct on As to the left face width was insignificant $(r=.01, t=0.03, p>.95)$. That is, 
this ability depended only upon the right face width, not the left face width.

\section{Dependence of Spatial Ability (Mental Rotation) on the Face Width}

The participants were the same as above. The Vandenberg and Kuse (1978) mental rotation test was administered to these students. This test is a timed, group-administered paper-and-pencil test, which requires participants to identify block figures that are identical to a standard figure except for their orientation. All instructions were translated into Turkish by native Turkish speakers who were also highly proficient in English (Halpern \& Tan, 2001). As also found, previously males performed significantly better than females in this test. This test was applied during the midluteal phase of the menstrual cycle in women, because this ability shows fluctuations during the menstrual cycle (Halpern \& Tan, 2001).

\section{Left-Handed Men}

The diagram in Figure 7 illustrates the relation of the mental-rotation ability (ordinate: number correct on mental rotation test) to the $\mathrm{R}-\mathrm{L}$ face width (abscissa). This ability positively linearly correlated with the $\mathrm{R}-\mathrm{L}$ face width $(r=.84, t=4.6, p=.001)$ : It increased as the right-facedness increased and decreased as the left-facedness increased. The lower diagram in Figure 7 illustrates the relation of the number correct on mental rotation (ordinate) to the right face width (closed circles, straight line) and the left face width (open circles, dashed line). The numbers correct on the mental rotation test positively linearly increased with the right face width $(r=.73, t=3.2$, $p=.01$ ), but the relation of this ability (numbers correct) to the left face width was statistically nonsignificant $(r=.36, t=-1.17, p>.25)$.

\section{Dependence of Spatial Ability on Face Width in Right-Handed Women ( $\mathrm{N}=24)$}

The upper diagram in Figure 8 illustrates the relation between the mental rotation ability (ordinate: number correct on mental rotation) 

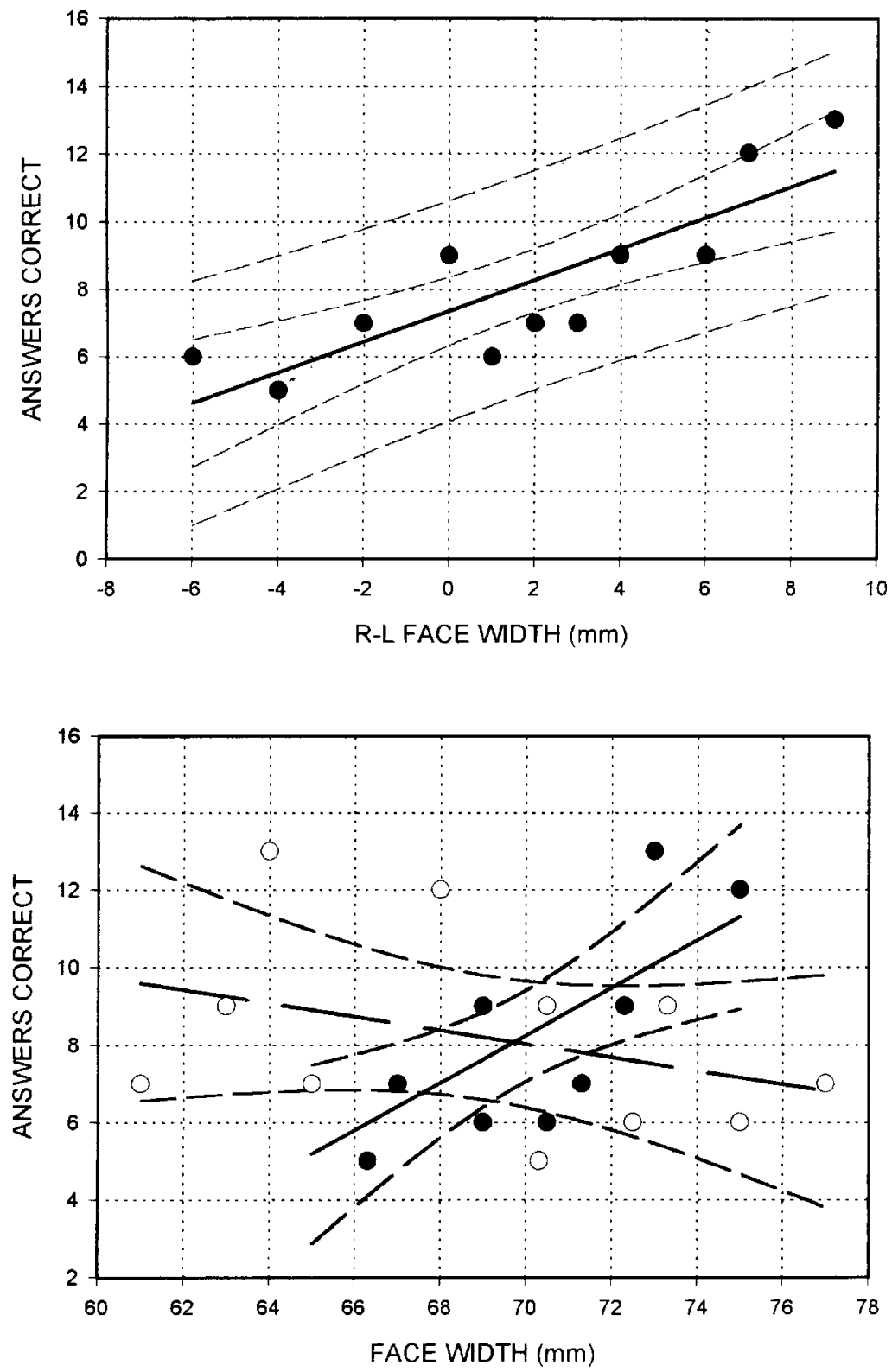

FIGURE 7. Relations of mental ability (number correct on mental rotation task) to $\mathrm{R}$ - L face width (top), and right (closed circles, straight line) and left face (open circles, dashed line) widths (bottom) in left-handed men. 



FIGURE 8. Relations of mental rotation ability (number correct on mental rotation task) to $\mathrm{R}$ - L face width (top), right face width (bottom: closed circles, straight line), and left face width (bottom: open circles, dashed line) for right-handed female subjects. 
and the $\mathrm{R}-\mathrm{L}$ face width (abscissa). The mental rotation ability positively and linearly correlated with the $\mathrm{R}-\mathrm{L}$ face width $(r=.72$, $t=4.9, p<.001)$. That is, this ability increased as the relative rightfacedness increased and decreased as the relative left-facedness increased. Considering the right and left face widths separately, there was no significant correlation between the mental rotation ability (ordinate) and the right face width (closed circles, straight line: $r=$ $.00, t=-0.01, p=.99$ ); there was a negative correlation between the number correct on mental rotation and the left face width in these subjects. This relation could be best described by a quadratic equation, which was statistically significant $\left(r=.78, F_{2,21}=15.9\right.$, $p<.001)$ : The mental rotation ability progressively decreased as the left face width increased. In men, the mental rotation ability did not show any significant relation to the $\mathrm{R}-\mathrm{L}$ face width, the right face width, and the left face width $(p>.05$ to .70$)$.

\section{DISCUSSION}

\section{Predictability of Hand Skill by Craniofacial Width}

The statistical analysis of the $\mathrm{R}-\mathrm{L}$ face width indicated that the female subjects were more right-faced $(57.7 \%)$ and less left-faced $(38.5 \%)$ than the male subjects who were less right-faced $(43.5 \%)$ and more left-faced $(52.2 \%)$ than the female subjects. Similar percentages for the paw preference were reported in cats (Tan, Yaprak, \& Kutlu, 1990): in females, 52.4\% right-pawed, 33.3\% left-pawed, and $14.3 \%$ ambidextrous; in males, $41.7 \%$ right-pawed, $50.5 \%$ leftpawed, and $8.3 \%$ ambidextrous. Tan and Kutlu (1991) further reported similar results in cats: in females, $54.0 \%$ right-pawed, 36.5\% left-pawed, and $9.5 \%$ ambidextrous; in males, $43.5 \%$ right-pawed, $45.7 \%$ left-pawed, and $10.9 \%$ ambidextrous. The authors have tentatively explained the origin of this distribution in pawedness by a female right-shift factor that would be required for the emergence of a right-bias in handedness; the absence of this factor would decrease the chance of being right-handed and increase the vulnerability of the developing brain to environmental influences. The human face width and the cats' paw preference share an important 
trait: they both are not subjected to social influences by their group members.

The close percentages for the human face width and cats' paw preference mentioned above suggest a structural-functional coupling between human face width and human handedness. An association between human craniofacial areas and hand preference was previously reported by Keles, Diyarbakirli, Tan, and Tan (1997). Interestingly enough, we have found in the present work that the hand skill of the subjects participated in this study exerted important relations to the measures of the facial width (see Figure 2). In the left-handed men, there was a negative linear correlation between the $\mathrm{L}-\mathrm{R}$ PMT and the $\mathrm{R}-\mathrm{L}$ face width. There were only a few left-handed women. Therefore, they were not included in the correlation analysis. This is the first study reporting a relation between the hand skill and a skeletal structure (face width). This result suggests that the functional brain would be associated with a bony structure outside the brain. The inverse correlation between the R $\mathrm{L}$ facial width and the $\mathrm{L}-\mathrm{R}$ PMT, that is, the difference between hands in skill, indicates that the asymmetry in facial width increases toward the right-facedness if left-hand skill increases in left-handedness; if the asymmetry in facial width decreases in right-facedness and increases in left-facedness, the difference in hand skill decreases in left-handedness. The $\mathrm{R}-\mathrm{L}$ face width depended only upon the left-face width (see Figure 1): The $\mathrm{R}-\mathrm{L}$ face width increased toward the right-facedness as the left face width decreased; the $\mathrm{R}$ - L face width decreased toward the left-facedness as the left face width increased.

According to the above mentioned results (see the upper diagram in Figure 2), the left-hand skill decreased toward ambilaterality as the left face width increased relative to the right face width; the lefthand skill increased toward the stronger left-handedness as the left face width decreased relative to the right face width. So, the left face width determines the degree of the left-hand skill in the lefthanded men. This result reflects the relation between brain and the left-hand skill. Accordingly, Tan (1990a) has previously reported that the mean R - L PMT linearly increased as the right-hand PMT increased. In other words, the left-hand skill increased as the righthand skill decreased, suggesting that the left-hand skill depends upon 
the relatively worse motor control of the left brain compared to the right brain in left-handed men. There was no significant correlation between the R - L PMT and the mean left-hand PMT. These results showed that the degree of the left-handedness in skill depends upon the left brain, not the right brain: a better developed motor control in the left brain may be related to a less developed left-hand skill and vice versa (see also Tan, 1990a, 1990b). Similarly, a better developed left face width was also associated with the less developed left-hand skill in left-handed male subjects in the present work. So, it may be concluded that left face width may be predictive for the motor efficiency of the left brain and the degree of the left-hand skill.

Contrary to the left-handed subjects, the $\mathrm{R}-\mathrm{L}$ face width increased positively and linearly as the L $-\mathrm{R}$ PMT increased in the right-handed subjects (see lower diagram in Figure 2). In other words, the right-hand skill increased as the left-facedness decreased and the right facedness increased. The $\mathrm{R}-\mathrm{L}$ face width depended upon the left face width in the right-handed female subjects (see the middle diagram in Figure 1), not the right face width: The right-facedness increased and the left-facedness decreased as the left face width decreased; the right-facedness decreased and the left-facedness increased as the left face width increased. In the right-handed male subjects, the facial width asymmetry depended upon both the right and left face widths as expected mathematically (see the lower diagram in Figure 2): The right-facedness increased as the right face width increased; the right-facedness decreased and the left-facedness increased as the left face width increased in these subjects. So, it can be concluded that facial asymmetry depends only upon the left face width in right-handed females, but on both the right and left face widths in right-handed males. These results conclude that the right brain is most important in determining the facial-width asymmetry in right-handers. In accord with these results, Tan, Ors, Kurkcuoglu, Kutlu, and Cankaya (1992b) have reported that there was a highly significant positive linear correlation between the $\mathrm{R}$ - L grasp-reflex strength and the grasp-reflex strength from the right hand in human newborns $(r=.74, p=.0000)$; the correlation between the $\mathrm{R}-\mathrm{L}$ grasp-reflex strength and the grasp-reflex strength was relatively weaker for the left hand $(r=.32, p=.0004)$ (see also Tan et al., 1992a). These coinciding results (facial asymmetry in 
adults and grasp reflex in newborns) suggest that the hand skill (brain), the facial asymmetry, and the grasp-reflex asymmetry all may be determined prenatally, having the same origins. In adults, Tan and Kutlu (1992) have stated that ". . . the left hand (right brain) would be of higher significance than the right hand (left brain) in determining the degree of the right-bias in hand skill and its stability in right-handers." So, the right-face in facedness and the right brain in hand skill are the most important structures determining facial and manual asymmetries.

\section{Predictability of "g" (Cattell) by the Facial Width}

It was expected that facial width may be associated with cognitive abilities in left- and right-handed subjects, because the PMT was previously reported to be related to IQ assessed by Cattell's Culture Fair Intelligence Test (e.g., Tan, 1989a, 1990b). Using Cattell's Culture Fair Intelligence Test, we have found that the $\mathrm{R}-\mathrm{L}$ facial width directly correlated with IQ in the left-handed subjects (see the lower diagram in Figure 3). IQ increased as right-facedness increased and decreased as the right-facedness decreased and left-facedness increased in these subjects. IQ increased linearly as the right face width increased (see the upper diagram in Figure 3). This correlation did not reach the traditional level of significance, however, probably because of the small sample size. Similarly, right-hand performance in dot-filling test increased linearly with IQ in lefthanders, but not the left-hand performance (see Tan, 1989a). There was an inverted U-shaped quadratic relation between IQ and the left face width in left-handed male subjects. Interestingly enough, a similar relation was found between IQ and the left-hand PMT; previously there was an optimal level of left-hand skill for the highest IQ similar to the relation between IQ and the left face width in left-handed men (see the middle diagram in Figure 3).

In right-handed female subjects, IQ inversely correlated with $\mathrm{R}-\mathrm{L}$ face width. That is, IQ decreased as right-facedness increased and left-facedness decreased; IQ increased as right-facedness decreased and left-facedness increased. In these subjects, however, IQ entirely depended upon right face width, not the left face width (see Figure 4A): IQ increased as right face width increased; IQ deceased as 
the right face width decreased. It is generally accepted that the right brain is involved in nonverbal-spatial abilities. So, this result indicating the importance of the right face width (right brain) suggests a relation of the right brain to the Cattell IQ. However, Willerman, Schultz, Rutledge, and Bigler (1992) have reported that a larger left hemisphere predicted relatively better nonverbal than verbal ability in women. Although these authors did not report right- and lefthanders separately, our results can also be interpreted in line of these authors. Namely, the R - L face width depended upon only the left face width in women as depicted by the middle diagram in Figure 1. On the other hand, IQ inversely correlated with the R - L face width in women. Visualizing these results together, it can be stated that IQ increases as the left face width increases and decreases as the left face width decreases. In right-handed men, IQ correlated positively and linearly with the $\mathrm{R}-\mathrm{L}$ face width. On the other hand, IQ directly correlated with the right face width and inversely correlated with the left face width (see Figure 4, lower diagram). That is, IQ depended upon both brain halves if face width is taken as reflecting brain width. These results suggest that the Cattell IQ in men may be predicted from the right and left face widths: The subjects with large right face width and small left face width may be good in this nonverbal IQ, and those with a small right face and large left face widths would not be good in Cattell IQ.

\section{Predictability of Perceptual-Verbal Ability from Face Width}

\section{Left-Handed Men}

This cognitive ability negatively linearly correlated with the $\mathrm{R}-\mathrm{L}$ face width (see Figure 5, upper diagram). That is, perceptual-verbal ability decreased as right-facedness increased and left-facedness decreased; IQ increased as right-facedness decreased and left-facedness increased in left-handed men. Because the $\mathrm{R}-\mathrm{L}$ face width depended only on left face width (see Figure 1, upper diagram), it may be stated that perceptual-verbal ability increases as the left face width increases, and decreases as left face width decreases. However, the number correct on As depended upon the right face width, not the left 
face width (see Figure 5, lower diagram). Considering the results in Figures 1 and 5 together, it is plausible to conclude that verbal ability may be predicted by left face width. This is in accord with the generally accepted knowledge that the left brain is dominant in about $70 \%$ of the left-handers for verbal functions in left-handers. The direct relation of right face width to verbal ability was obtained by independent analysis of right and the left face widths, suggesting that the right face may also be involved in verbal-perceptual ability. Consistent with the prominent role of left brain (left face) in verbal ability, Willerman et al. (1992) have reported that a relatively larger left brain predicted better verbal ability than nonverbal ability, but they did not report the handedness of their subjects.

\section{Right-Handed Men}

There was a negative linear correlation between the verbal ability (number correct on As) and the $\mathrm{R}$ - L face width in right-handed male subjects (see Figure 6A). That is, the verbal ability increased as the right-facedness decreased and the left-facedness increased as was seen in the left-handed men. Since the $\mathrm{R}-\mathrm{L}$ face width depended on the right and left face widths in the right-handed men (see Figure 1, lower diagram), it can be concluded that the verbal ability increases as the right face width decreased and the left face width increases; the verbal ability decreased as the right face width increases and the left face width decreases. This result is more or less consistent with Willerman et al. (1992) who reported that a relatively larger left hemisphere predicted better verbal than nonverbal ability. However, if the right and left face widths were considered as independent variables, we have found that the right face width would directly determine verbal ability. This is, however, not in accord with the generally accepted notion about cerebral laterality for the verbal ability, but suggests that the right brain (right face) would also contribute to perceptual-verbal ability in right-handed men.

\section{Right-Handed Women}

The perceptual-verbal ability was found to be directly related to the $\mathrm{R}-\mathrm{L}$ face width in the right-handed female subjects (see Figure 
6C). That is, this ability increased as right-facedness increased and left-facedness decreased; this ability decreased as right-facedness decreased and left-facedness increased. Because the $\mathrm{R}-\mathrm{L}$ face width depended only upon the left face width (see Figure 1, middle diagram) in these subjects, it may be concluded that the perceptualverbal ability in right-handed women increased as the left face width decreased and decreased as the left face width increased. When the right and left face widths were taken separately (see Figure 6D), it was found that the right face width was directly correlated with verbal ability. This coincides with the result in Figure 6C and suggests that the right face width would also contribute to the perceptual-verbal ability in right-handed women.

\section{Predictability of the Mental Rotation Ability from Face Width}

\section{Left-Handed Men}

Mental rotation ability was found to be directly related to $\mathrm{R}-\mathrm{L}$ face width in left-handed male subjects in the present work (see Figure 7, upper diagram): The number correct on mental rotation task increased as right-facedness increased and left-facedness decreased and vice versa. It was also found that right face width directly related to mental rotation ability (see Figure 7, lower diagram). Taken together, it can be concluded that mental rotation ability increases as the right face width increases and the left face width decreases; mental rotation ability decreases as the left face width increases and the right face width decreases.

\section{Right-Handed Women}

There was a direct relation between mental rotation ability (number correct on mental rotation task) and the $\mathrm{R}-\mathrm{L}$ face width (see Figure 8, upper diagram): This cognitive ability increased as rightfacedness increased and left-facedness decreased, and decreased as right-facedness decreased and left-facedness increased. This relation seemed to be related to the left face width, because there was a negative quadratic relation between the mental rotation ability and 
the left face width only (see Figure 8, lower diagram). In accordance with the result shown in Figure 8 (upper diagram), the mental rotation ability decreased as the left face width increased and increased as the left face width decreased. We could not find any significant relation between this ability and the face widths in righthanded men.

\section{Face Width, Hand Skill, and Intelligence: Relation of Structure to Function}

The results of the present work provided important examples for the relation of structure to function. It was found that there are correlations among right and left face widths, $\mathrm{R}-\mathrm{L}$ face widths, hand skill, verbal IQ (A's Test), and nonverbal IQ (Cattell's Culture Fair Intelligence Test and mental rotation ability). Handedness has indeed been shown to be related to the morphology of the occlusal teeth (Pirila-Parkkinen et al., 2001). These intercorrelations suggest a common origin for this structural-functional coupling. The results of the present work highlight the interdependence of a craniofacial measure, facial width, with handedness, and cognitive abilities with their complex interactions. This may be possible by a orchestrated integration of multiple specialized tissue interactions (see Trainor \& Krumlauf, 2001). The head as a whole is composed of the nervous system, axial skeleton, muscles, and connective tissues. In the vertebrate embryo, the cranial neural crest is a pluripotent population playing a role in construction of the head. The cells of the cranial neural crest form nerves, ganglia, cartilage, bone, and connective tissue (Trainor \& Krumlauf, 2001). So, the orchestrated integration of the structural-functional coupling revealed in the present work may share a common origin during the development of the human embryo.

It was frequently reported that a close interconnection exists between the development of the face, the craniofacial skeleton, and the brain, suggesting a genetic origin for this integrative function. Accordingly, DIx genes from the homeobox family are expressed in craniofacial primordia, basal telencephalon, and diencephalon, and in distal regions of extending appendages, including the limb and the genital bud; they are expressed in differentiating osteoblasts to 
form, for instance, the craniofacial patterning, sensory organ morphogenesis, and osteogenesis (Merlo et al., 2000). Normal development of the face, eyes, and brain requires the coordinated expression of many genes, the gene sonic hedgehog that has been implicated in the development of each of these structures encodes the secreted protein (Nasrallah \& Golden, 2001). Many disorders have their origins in specific embryological processes, including abnormalities of brain patterning, of the migration and fusion of tissues in the face, and of bone differentiation in the skull vault (Wilkie \& Morriss-Kay, 2001). The clefts of the lip and palate are developmental craniofacial abnormalities often associated with cognitive dysfunction. For instance, Nopoulos et al. (2001) have found low IQ in patients with clefts of the lip and palate and concluded that the development of the face and the brain are intimately related; defects in craniofacial development are most likely linked to the defects in brain development. The above studies indicate that the craniofacial region, brain, and cognition develop in parallel sharing the same genetic origin. Consequently, the relation of facial width to hand skill and cognitive abilities may have the same genetic origins.

\section{REFERENCES}

Blaschke, R. J., Monaghan, A. P., Schiller, S., Schehinger, B., Rao, E., Padilla-Nash, H., Ried, T., \& Rappold, G. A. (1998). SHOT, a SHOX-related homeobox gene, is implicated in craniofacial, brain, heart, and limb development. Proceedings of National Academy of Sciences, USA, 95, 2406-2411.

Cattell, R. B. (1987). Intelligence: Its structure, growth, and action. Advances in Psychology, 35, 14-59.

Cohen, S. R., Corrigan, M. L., Bookstein, F. L., Trotman, C. A., Burdi, A., \& Barr, M. (1995). Log-linear allometry of fetal craniofacial growth in Down's syndrome. Journal of Craniofacial Surgery, 6, 184-189.

Dirksen, M. L., Mathers, P., \& Jamrich, M. (1993). Expression of a Xenopus distal-less homeobox gene involved in forebrain and cranio-facial development. Mechanisms of Development, 41, 121-128.

Farkas, L. G., Katic, M. J., Forrest, C. R., \& Litsas, L. (2001). Surface anatomy of the face in Down's syndrome: Linear and angular measurements in the craniofacial regions. Craniofacial Surgery, 12, 373-379.

Farkas, L. G., Munro, I. R., \& Kolar, J. C. (1985). Abnormal measurements and disproportions in the face of Down's syndrome patients: Preliminary report of an anthropometric study. Plastic and Reconstructive Surgery, 75, 159-169.

Godfrey, L. R., Samonds, K. E., Jungers, W. L., \& Sutherland, M. R. (2001). Teeth, brains, and primate life histories. American Journal of Physical Anthropology, 114, 192-214. 
Halpern, D. F., \& Tan, U. (2001). Stereotypes and steroids: Using a psychobiosocial model to understand sex differences. Brain and Cognition, 45, 392-414.

Handoll, N. J. R. (1998). The osteopathic management of children with Down's syndrome. British Osteopathic Journal, 21, 11-20.

Keles, P., Diyarbakirli, S., Tan, M., \& Tan, U. (1997). Facial asymmetry in right- and lefthanded men and women. International Journal of Neuroscience, 91, 147-160.

Kimura, D., \& Hampson, E. (1994). Cognitive pattern in men and women is influenced by fluctuations in sex hormones. Current Directions in Psychological Science, 3, $57-61$.

Merlo, G. R., Zerega, B., Paleari, L., Trombino, S., Mantero, S., \& Levi, G. (2000). Multiple functions of DIx genes. International Journal of Developmental Biology, 44, 619-626.

Nasrallah, I., \& Golden, J. A. (2001). Brain, eye, and face defects as a result of ectopic localization of sonic hedgehog protein in the developing rostral neural tube. Teratology, 64, 107-113.

Nopoulos, P., Berg, S., VanDemark, D., Richman, L., Canady, J., \& Andreasen, N. C. (2001). Increased incidence of a midline brain anomaly in patients with nonsyndromic clefts of the lip and/or palate. Journal of Neuroimaging: Official Journal of the American Society of Neuroimaging, 11, 418-424.

Pirila-Parkkinen, K., Pirttiniemi, P., Alvesalo, L., Silven, O., Heikkila, J., \& Osborne, R. H. (2001). The relationship of handedness to asymmetry in the occlusal morphology of first permanent molars. European Journal of Morphology, 39, 81-89.

Rushton, J. P., \& Ankney, C. D. (1996). Brain size and cognitive ability: Correlations with age, sex, social class, and race. Psychonomic Bulletin and Review, 3, 21-36.

Tan, U. (1988). The distribution of hand preference in normal men and women. International Journal of Neuroscience, 41, 35-55.

Tan, U. (1989a). Manual proficiency in Cattell's Intelligence Test in left-handed male and female subjects. International Journal of Neuroscience, 44, 17-26.

Tan, U. (1989b). Right and left hand skill in left-handers: Distribution, learning, and relation to nonverbal intelligence. International Journal of Neuroscience, 44, 235249.

Tan, U. (1990a). The left brain determines the degree of left-handedness. International Journal of Neuroscience, 53, 75-85.

Tan, U. (1990b). Relation of hand skill to spatial reasoning in male and female lefthanders with left- and right-hand writing. International Journal of Neuroscience, 53, 121-133.

Tan, U., \& Kutlu, N. (1991). The distribution of paw preference in right-, left-, and mixed-pawed male and female cats: The role of a female right-shift factor in handedness. International Journal of Neuroscience, 59, 219-229.

Tan, U., \& Kutlu, N. (1992). Right and left hand skill in relation to cerebral-lateralization in right-handed male and female subjects: The prominent role of the right brain in right-handedness. International Journal of Neuroscience, 64, 125-138.

Tan, U., Ors, R., Kurkcuoglu, M., \& Kutlu, N. (1992a). The lateralization of the grasp reflex in human newborns. International Journal of Neuroscience, 62, 1-8.

Tan, U., Ors, R., Kurkcuoglu, M., Kutlu, N., \& Cankaya, A. (1992b). Lateralization of the grasp reflex in male and female human newborns. International Journal of Neuroscience, 62, 155-163.

Tan, U., \& Tan, M. (1998). Curvelinear correlations between total testosterone levels and fluid intelligence in men and women. International Journal of Neuroscience, 95, 7783.

Tan, U., Tan, M., Polat, P., Ceylan, Y., Suma, S., \& Okur, A. (1999). Magnetic resonance imaging brain size/IQ relations in Turkish university students. Intelligence, 27, 83-92.

Tan, U., Yaprak, M., \& Kutlu, N. (1990). Paw preference in cats: Distribution and sex differences. International Journal of Neuroscience, 50, 195-208. 
Trainor, P. A., \& Krumlauf, R. (2001). Hox genes, neural crest cells and branchial arch patterning. Current Opinion in Cell Biology, 13, 698-705.

Vandenberg, S. G., \& Kuse, A. R. (1978). Mental rotation: A group test of three-dimensional spatial visualization. Perceptual and Motor Skills, 47, 599-601.

Wilkie, A. O. M., \& Morriss-Kay, G. M. (2001). Genetics of craniofacial development and malformation. Nature Reviews Genetics, 2, 458-468.

Willerman, L., Schultz, R., Rutledge, J. N., \& Bigler, E. D. (1992). Hemisphere size asymmetry predicts relative and nonverbal intelligence differently in the sexes-an MRI study of structure-function relations. Intelligence, 16, 315-328. 